\title{
Mensuração do capital intelectual docente: avaliação e reconhecimento por meritocracia em uma instituição de ensino superior
}

\author{
Leonardo Santos Ferreira ${ }^{I}$ \\ Maria Celeste Reis Lobo Vasconcelos ${ }^{I I}$ \\ https://orcid.org/0000-0002-8383-9375 \\ Frederico Cesar Mafra Pereira III \\ https://orcid.org/0000-0002-1971-8069
}

I Centro Universitário UNA, Belo Horizonte, MG, Brasil. Mestre em Administração pela Fundação Pedro Leopoldo. Docente no Centro Universitário UNA.

II Fundação Pedro Leopoldo, Pedro Leopoldo, MG, Brasil.

Docente do Corpo Permanente do Mestrado Profissional em Administração.

Doutora em Ciência da Informação pela Universidade Federal de Minas Gerais.

III Fundação Pedro Leopoldo, Pedro Leopoldo, MG, Brasil.

Docente do Corpo Permanente do Mestrado Profissional em Administração.

Doutor em Ciência da Informação pela Universidade Federal de Minas Gerais.

\section{http://dx.doi.org/10.1590/1981-5344/3866}

As Instituições de Ensino Superior Privadas (IES), em sua grande maioria, não possuem modelo de avaliação de Ativos Intangíveis, impossibilitando a valorização dos seus docentes com base nos seus resultados, remunerando-os somente pela titulação. Esta pesquisa analisa um programa para mensurar o Capital Intelectual Docente numa IES Privada, visando à avaliação e ao reconhecimento por meritocracia. A pesquisa foi classificada como um estudo de caso descritivo. Foi utilizada uma abordagem qualitativa, na realização da entrevista com a Alta Direção e quantitativa, na aplicação de questionário para os professores. Foi também feita pesquisa documental, na análise do edital do Programa de Reconhecimento do Mérito Docente (PRMD), proposto pela IES pesquisada. Da população de 743 professores, 162 participaram da pesquisa. Os resultados apontaram algumas possíveis melhorias: extensão da amplitude do 
PRMD, mudanças na comunicação interna, revisão do critério de pontuação e mensuração do programa, o uso do currículo Lattes para extrair as atividades acadêmicas dos docentes, mudança das políticas internas, melhoria dos sistemas de informações e melhor valorização dos colaboradores. Conclui-se que $o$ uso correto das estratégias e dos indicadores adequados para 0 gerenciamento dos Ativos Intangíveis pode agregar valor para os docentes e para a instituição.

Palavras-chave: Gestão do Conhecimento. Ativos Intangíveis. Mensuração do Capital Intelectual. IES Privada. Meritocracia.

\section{Measurement of faculty body intellectual capital: evaluation and recognition by meritocracy in an institution of higher education}

Private Higher Education Institutions (HEI), in their vast majority, do not have an Intangible Assets valuation model, making it impossible to value their professors based on their results, who are then remunerated only by their titles. This research analyzes a program to measure the Faculty Body Intellectual Capital in a Private HEI, aiming at their evaluation and recognition by meritocracy. The research was classified as a descriptive case study. It was used a qualitative approach, in the interviews with the high direction and quantitative, in the questionnaire for the professors. A documentary research was also done in the analysis of the Program of Recognition of Faculty Body Merit (PRFBM), proposed by the IES. Of the 743 members of the faculty body, 162 participated in the research. The results pointed to some possible improvements: extension of PRFBM amplitude, changes in internal communication, revision of the punctuation criteria of the program, use of the Lattes curriculum to extract academic activities from teachers and improvement of the information system. It is concluded that the use of adequate strategies and indicators for the management of Intangible Assets can add value to the faculty body and to the institution. 
Mensuração do Capital Intelectual Docente: Avaliação e Reconhecimento por Meritocracia em uma Instituição de Ensino Superior
Leonardo Santos Ferreira; Maria Celeste Reis Lobo Vasconcelos; Frederico Cesar Mafra Pereira

Keywords: Knowledge Management. Intangible Assets. Intellectual Capital Measurement. Private HES. Meritocracy.

Recebido em 20.02.2019 Aceito em 01.11.2019

\section{Introdução}

Com a existência e o surgimento de novas tecnologias e serviços, as empresas necessitam adequar-se a uma nova realidade. O conhecimento se torna um patrimônio estratégico. Em decorrência, as pessoas têm maior importância nas organizações, por isso são vistas, não como despesas, mas sim como ativos da empresa, devido ao fato de elas produzirem todo o Capital Intelectual que proporciona um diferencial competitivo para as organizações (BASSAN; HAUSCHILDT, 2005). Observa-se que a avaliação dos Ativos Intangíveis (AI) é importante para o desenvolvimento e a valorização equitativa das organizações e de seus colaboradores, impulsionando-os na busca da excelência e agregação de valor no mercado (TERRA, 2000; VASCONCELOS, 2000).

De acordo com Edvinsson e Malone (1998), o capital intelectual é imprescindível para mensuração do desempenho corporativo, expondo o valor real e restaurando o senso de justiça e igualdade de direitos que devem prevalecer na economia.

Observa-se, entretanto, que a grande maioria das Instituições de Ensino Superior (IES) não possui ferramentas para avaliação de seus ativos intangíveis, tornando difícil mensurar o seu Capital Intelectual Docente e, por consequência, inviabilizando o reconhecimento dos seus professores por meritocracia (CAJUEIRO, 2008; GOMES, 2014). Muitas delas se pautam pelo padrão de remuneração já existente, usando como base, apenas, a titulação do docente. De acordo com o Sindicato dos Professores de Minas Gerais (SINPRO/MG), a hora-aula dos docentes é determinada pelo título de especialista, mestre ou doutor que ocupam respectivamente o cargo de professor auxiliar, professor assistente ou professor adjunto, sendo que em algumas IES há o cargo de professor titular (SINPRO, 2015).

A finalidade desta pesquisa é avaliar mecanismos que possam ser aplicados nas IES e que permitam ir além da valorização pela titulação já aplicada atualmente. Havendo esse reconhecimento, os docentes serão remunerados e bonificados não somente por sua titulação, mas também por sua produtividade.

A pesquisa foi realizada numa Instituição de Ensino Superior - IES, que, de maneira inovadora, desenvolveu e aplicou um Programa de Reconhecimento do Mérito Docente - PRMD em 2016. Entretanto, faltava uma avaliação geral do mesmo, pela direção e pelos docentes.

Com base no contexto acima, o principal objetivo do estudo foi: analisar a aplicação do PRMD em uma IES, visando à avaliação e ao reconhecimento por meritocracia. Outros objetivos foram: 
i) analisar a estratégia da diretoria da IES na aplicação do Programa e os resultados da implementação;

ii) analisar a percepção dos docentes da IES com relação aos critérios propostos;

iii) identificar possíveis melhorias do Programa, com base nos resultados da pesquisa.

É importante ressaltar que não foram identificados na literatura outros programas relacionados à mensuração do capital intelectual docente em IES com foco na avaliação e no reconhecimento por meritocracia.

Para atingir seus objetivos, o artigo foi estruturado em cinco tópicos, incluindo esta introdução, que apresenta a contextualização do tema e os objetivos da pesquisa. No tópico dois são discutidos os desafios da mensuração dos ativos intangíveis. A metodologia é apresentada no tópico três, os resultados são analisados e discutidos no tópico quatro e as considerações finais no tópico cinco.

\section{Mensuração dos ativos intangíveis}

Os ativos intangíveis, apesar de desempenharem papel importante no desenvolvimento e na valorização da maioria das organizações, normalmente não são evidenciados devido à dificuldade de sua mensuração (BEUREN; IGARASHI, 2002; RITTA; ENSSLIN, 2010).

Estes Ativos podem criar valores adicionais para a organização. Esse ponto de vista é embasado no potencial único de cada indivíduo contribuir para a empresa. Esse tipo de recurso é de difícil absorção por parte dos concorrentes, podendo, então, ampliar receitas e capacidade inovadora (PEREIRA; MAFRA PEREIRA; VASCONCELOS; FERREIRA, 2015). Os Ativos Intangíveis de uma empresa podem ser medidos e avaliados pela contabilidade. Martinez (1999) relata que, em 1994, a Skandia se tornou a primeira companhia a publicar, junto com suas declarações financeiras, suplementos especiais que medem o Capital Intelectual (CI). O autor afirma que o gerenciamento do CI por parte da Skandia tem demonstrado ser um instrumento administrativo efetivo.

Para Stewart (1998), o material intelectual é uma combinação de conhecimento, informação, propriedade intelectual, sendo que a experiência, para gerenciar estes ativos, gera valores organizacionais. 0 autor entende que o conhecimento pertence ao indivíduo e não às organizações e, portando, há dificuldade em registrar estes ativos nas demonstrações contábeis. Feitosa (2015), com a mesma percepção de Stewart (1998), afirma que, por mais perceptível que seja a valorização dos ativos intangíveis, ainda existe muita dificuldade para mensurar e registrar tais ativos.

O Capital Intelectual é um ativo intangível e é definido por Pereira e outros como sendo 
a criação de novos conhecimentos pela empresa que passam pela conversão de conhecimentos tácitos (experiências pessoais, know how, motivações, insights e visões de mundo) em conhecimentos explícitos (manuais, fórmulas, procedimentos), passíveis de serem reutilizados pela organização de forma estratégica (PEREIRA et.al, 2015, p. 279).

De acordo com Edvinsson e Malone (1998), o Capital Intelectual é imprescindível para mensuração do desempenho corporativo, expondo o valor real e restaurando o senso de justiça e igualdade de direitos que devem prevalecer na economia. Mesmo sendo um ativo intangível, o capital intelectual pode ser agrupado e mensurado. Os indicadores de mensuração contemplam a contabilidade, fornecendo informações úteis, já que ela necessita de demonstrações contábeis com informações de natureza intelectual, humana, ecológica e social. As informações geradas com a mensuração dos ativos intangíveis são extremamente úteis para a tomada de decisão a respeito de clientes, de pessoal e de investimentos.

\subsection{Modelos de mensuração dos ativos intangíveis}

Alguns modelos têm sido propostos por diversos autores no que diz respeito à mensuração dos ativos intangíveis. Entre os modelos cita-se o intitulado como Modelo de Controle do Capital Intelectual estudado por Jordão, Casas Novas, Souza e Neves (2013). Neste modelo (Figura 1), a geração de valor na empresa acontece fundamentada na metodologia do Market Value Added (MVA) que funciona "de modo a mensurar o valor dos ativos intelectuais e/ou intangíveis em termos financeiros em nível organizacional, de forma a observar a contribuição do CI no valor de mercado" (MELO, 2015, p. 65). 
Figura 1 - Modelo de Controle do Capital Intelectual

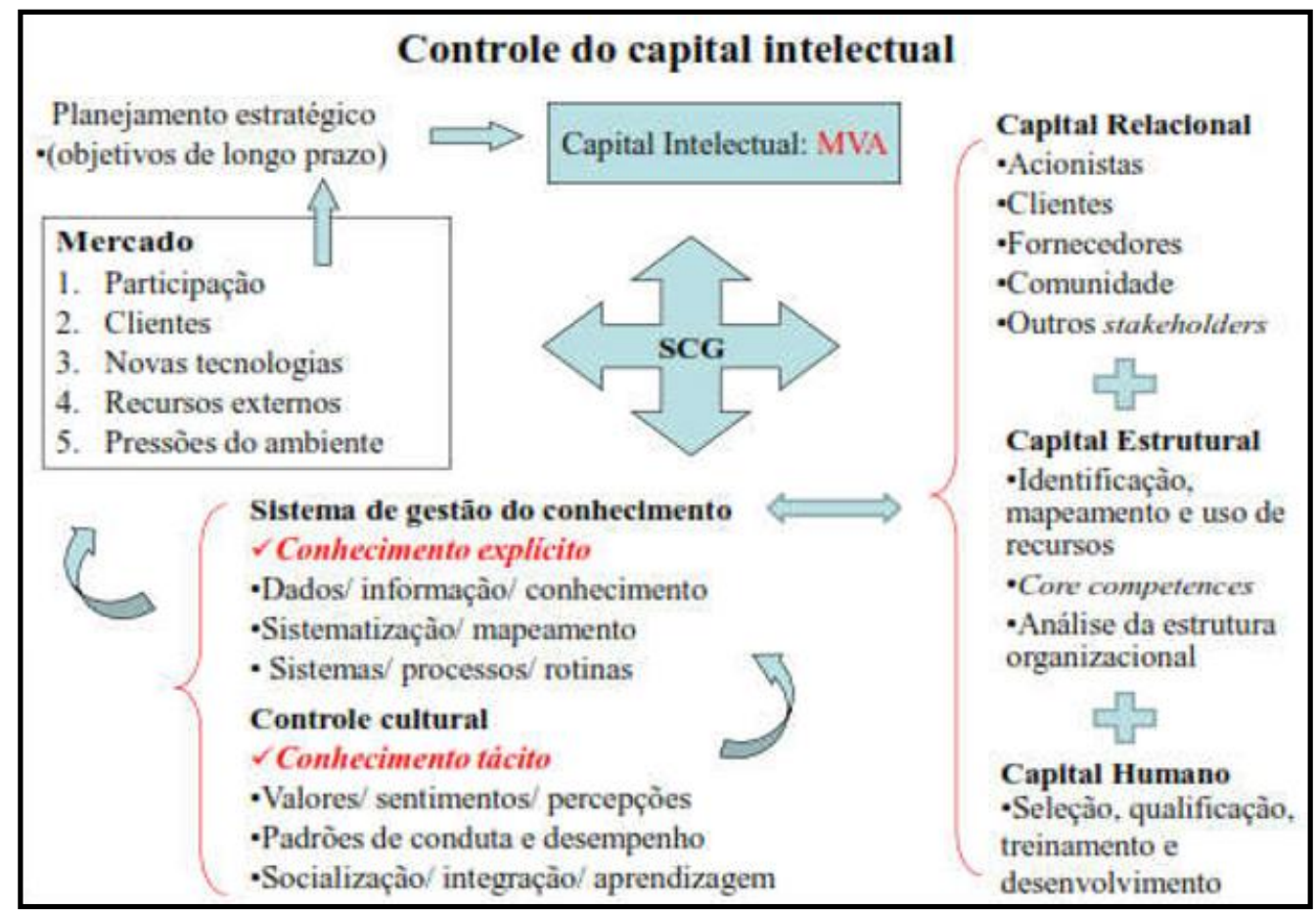

Fonte: JORDÃO, et al., 2013, p. 211).

Para os autores, o Sistema de Gestão do Conhecimento colabora para incremento do CI e, ao mesmo tempo, se beneficia da estrutura da empresa estabelecida para incorporar o conhecimento oriundo do capital humano e relacional.

O Modelo de Controle do Capital Intelectual ajuda no processo de conversão de parte do conhecimento tácito em conhecimento explícito, facilita o processo da integração do Sistema de Gestão do Conhecimento (SCG) com a estratégia e a cultura organizacional. Ele mostra como o controle cultural pode contribuir para o estabelecimento de um efetivo SCG sobre o CI. A premissa central é que o controle cultural colabora na sistematização de parte dos conhecimentos formadores do CI por meio das atividades de socialização dos valores individuais e da internalização dos valores coletivos inerentes à formação da cultura organizacional.

\subsection{Modelo para mensuração do capital intelectual docente}

Ao longo do tempo, pode-se observar a evolução e relevância que o tema vem assumindo. Apesar de a literatura abordar mais a valorização destes ativos intangíveis para organizações industriais, o estudo dos ativos intangíveis em Instituições de Ensino Superior (IES) vem crescendo.

O aumento dos estudos voltados para IES é o reflexo da evolução na economia do conhecimento. Com a facilidade e o acesso às IES, inúmeras instituições vêm, cada dia mais, exigindo dos gestores mudanças nos quadros organizacionais, pois querem profissionais qualificados $e$ preparados para atuar com eficiência e qualidade. A exigência por 
melhorias vem por parte das políticas educacionais e por parte dos clientes (FEITOSA, 2015).

Uma pesquisa realizada com professores e coordenadores de um Mestrado Profissional em Administração (MPA), buscou identificar as necessidades de elaborar um modelo para avaliar o Capital Intelectual em Instituições de Ensino Superior no Brasil (PEROBA, 2013).

Com os resultados obtidos na pesquisa, Peroba (2013) propôs um modelo baseado em outros dois já consolidados, sendo eles o modelo de "Demonstração de Capital Intelectual utilizado pelas universidades austríacas (Wissensbilanz) e a "Demonstração de Capital Intelectual das Universidades Intelectual Capital of Universities (ICU) elaborado pelo Observatório das Universidades Europeias (OEU)" (PEROBA, 2013, p 162).

O modelo proposto por Peroba (2013) é mais alinhado às Instituições Superiores do Brasil. Possui três seções, sendo elas:

i) Plano Estratégico;

ii) Ativos Intangíveis Críticos;

iii) Indicadores de Capital Intelectual separados em dimensões (Capital Estrutural, Capital Relacional e Capital Humano).

Com foco na classificação dos indicadores relacionados aos cursos de mestrado em administração, Peroba (2013) apresenta uma estrutura, conforme Figura 2, para identificação e classificação dos indicadores do Capital Intelectual.

Figura 2 - Classificação dos Indicadores de Capital Intelectual dos Cursos

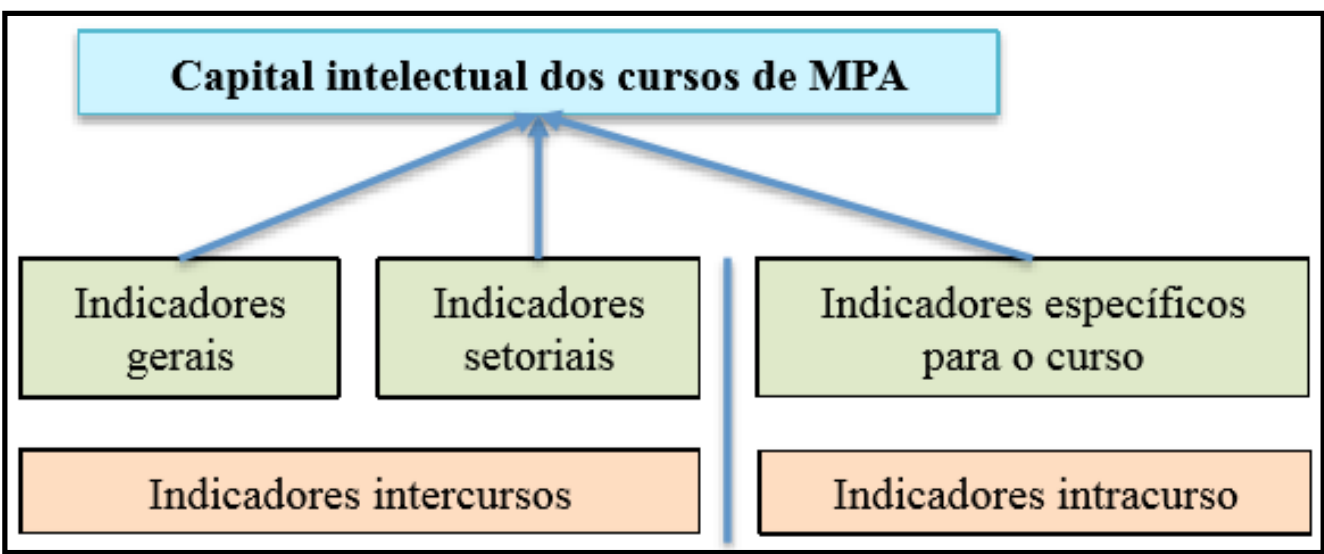

Fonte: PEROBA, T.L.C, 2013, p.186

Os indicadores do modelo de Peroba (2013) são agrupados em cinco grupos.

i) Indicadores gerais são ligados às metas da instituição.

ii) Indicadores setoriais são os indicadores específicos para as atividades (setoriais), apresentam indicadores aplicáveis a todos os cursos. 
iii) Indicadores específicos são os indicadores definidos para o curso, e que são aplicados apenas ao curso avaliado, por estarem relacionados aos seus objetivos estratégicos.

iv) Indicadores intercursos promovem comparações por meio da adoção de indicadores do mesmo grupo, por diferentes instituições em um dado período de tempo.

v) Indicadores intracursos promovem o acompanhamento da evolução do Capital Intelectual da instituição avaliada ao longo do tempo. Como resultado dessa análise interna, os usuários do demonstrativo poderão avaliar os resultados, acompanhar a evolução ou involução dos números apresentados e o atendimento às metas e aos objetivos estratégicos delineados.

Os indicadores apresentados no modelo de Peroba (2013) procuram promover, não somente a comparação entre cursos, mas também acompanhar os objetivos e as metas específicas da instituição traçadas para o período analisado.

\subsection{Programa de reconhecimento do mérito docente - PRMD de uma IES mineira}

Com o objetivo de reconhecer o mérito docente da instituição, uma IES mineira desenvolveu e propôs em 2015 o Programa de Reconhecimento do Mérito Docente - PRMD, política que estabelece normas e critérios para o reconhecimento do papel do professor, por meio da meritocracia, considerada fundamental na construção de uma experiência universitária visando um alto nível de aprendizagem e de desenvolvimento dos alunos.

Para o reconhecimento do mérito docente, foram estabelecidos normas e critérios, com diferentes dimensões. Para cada dimensão, foram propostos diferentes indicadores.

i) Dimensão Pedagógica - Visa reconhecer os méritos docentes relacionados à promoção efetiva da aprendizagem de seus alunos, valorizando-se as práticas pedagógicas adotadas pelo docente, a capacidade de usar a avaliação como instrumento de aprendizagem e o domínio e produção técnica, científica e cultural;

ii) Dimensão Envolvimento - Serão reconhecidos os esforços e a dedicação do docente no suporte às estratégias acadêmicas de sua Instituição e apoio à coordenação e direção;

iii) Dimensão Mentoria - Será reconhecido o comprometimento do docente com o futuro de seus alunos, considerando o papel que exerce enquanto mentor, orientador e fonte de inspiração profissional.

iv) Avaliação de Desempenho - Será considerada a avaliação do desempenho do docente, feita pelos Coordenadores dos Cursos nos quais leciona, como parte do Programa de Gestão de Desempenho que ocorre uma vez a cada ano. 


\section{Procedimentos metodológicos}

Quanto aos fins, a pesquisa foi caracterizada como um estudo de caso descritivo com uma abordagem quantitativa e qualitativa, a fim de explorar a mensuração do Capital Intelectual Docente na IES pesquisada (COLLIS; HUSSEY, 2005; MARCONI; LAKATOS, 2011). Quanto aos meios a pesquisa foi caracterizada como documental, em busca de informações em documentos que não receberam nenhum tratamento científico (OLIVEIRA, 2007) e de campo em prol da investigação empírica em uma instituição onde ocorre um fenômeno (VERGARA, 2015).

A unidade de análise foi o PRMD, proposto por uma instituição de ensino superior privada com dezessete unidades em Minas Gerais, situadas nas cidades de Belo Horizonte, Betim, Bom Despacho, Contagem, Divinópolis, Itabira, Pouso Alegre, Sete Lagoas e Uberlândia e duas unidades em Goiás, situadas nas cidades Catalão e Jataí. Atuando no mercado acadêmico há 57 anos, essa instituição vem oferecendo formação profissional em diversas áreas da atuação: cursos de graduação, graduação tecnológica, especialização lato sensu e stricto sensu. A unidade de observação foi constituída por professores e por membros da Alta Direção.

A pesquisa de campo foi realizada em 3 etapas, nesta ordem:

i) entrevistas com a alta administração para identificar quais foram os objetivos que levaram à implantação do PRMD e saber se esses objetivos foram alcançados;

ii) aplicação de questionário aos docentes para analisar a percepção dos mesmos com relação aos critérios propostos no PRMD. O questionário foi desenvolvido pelos autores da pesquisa, com base nas dimensões propostas no PRMD, utilizando-se a escala Likert de cinco pontos. O resumo do questionário se encontra na Quadro 1;

iii) questão aberta, disponibilizada no fim do questionário, para que os docentes apontassem pontos de melhoria para o PRMD.

Quadro 1 - Resumo do questionário aplicado aos docentes

\begin{tabular}{|c|l|}
\hline Questões & \multicolumn{1}{c|}{ Afirmativas } \\
\hline 1 & $\begin{array}{l}\text { A Dimensão Pedagógica engloba todas as categorias necessárias para o reconhecimento por } \\
\text { meritocracia, relacionados à promoção efetiva da aprendizagem dos alunos, valorização de } \\
\text { práticas pedagógicas, o uso da avaliação como instrumento de aprendizagem e o domínio e } \\
\text { produção técnica, científica e cultural. }\end{array}$ \\
\hline 2 & $\begin{array}{l}\text { A Dimensão Envolvimento engloba todas as categorias necessárias para o reconhecimento por } \\
\text { meritocracia, avaliando os esforços e a dedicação do professor no suporte às estratégias } \\
\text { acadêmicas de sua Instituição e apoio à coordenação e direção }\end{array}$ \\
\hline 3 & $\begin{array}{l}\text { A Dimensão Mentoria engloba todas as categorias necessárias para reconhecimento por } \\
\text { meritocracia, reconhecendo o comprometimento do docente com o futuro de seus alunos, } \\
\text { enquanto mentor, orientador e fonte de inspiração profissional. }\end{array}$ \\
\hline 4 & $\begin{array}{l}\text { A Dimensão Avaliação de Desempenho engloba todas as categorias necessárias para } \\
\text { reconhecimento por meritocracia, usando como base a avaliação APRIMORA (feita uma vez } \\
\text { por ano) na qual os coordenadores dos cursos em que o professor leciona o avaliam. }\end{array}$ \\
\hline 5 & No Simpósio foi divulgado que não houve, por parte dos professores, a adesão ao PRMD que \\
\hline
\end{tabular}


Mensuração do Capital Intelectual Docente: Avaliação e Reconhecimento por Meritocracia em uma Instituição de Ensino Superior
Leonardo Santos Ferreira; Maria Celeste Reis Lobo Vasconcelos; Frederico Cesar Mafra Pereira

\begin{tabular}{|c|l|}
\hline & se esperava. \\
\hline 6 & $\begin{array}{l}\text { Na oportunidade foi divulgado também que ocorreram alguns imprevistos que interferiram no } \\
\text { processo de tabulação para mensuração dos indicadores e obtenção dos resultados. }\end{array}$ \\
\hline 7 & $\begin{array}{l}\text { Os critérios para mensuração dos indicadores e pontuação do PRMD foram bem } \\
\text { definidos/planejados }\end{array}$ \\
\hline 8 & Os requisitos utilizados para a premiação/bonificação do PRMD foram satisfatórios \\
\hline 9 & No contexto geral, a implementação do PRMD obteve sucesso junto ao corpo docente \\
\hline 10 & $\begin{array}{l}\text { O instrumento de mensuração utilizado no PRMD ajuda a entender melhor os conhecimentos } \\
\text { que devem ser geridos }\end{array}$ \\
\hline 11 & $\begin{array}{l}\text { O PRMD contribui para a IES ser vista como uma IES que pratica o reconhecimento por } \\
\text { meritocracia. }\end{array}$ \\
\hline & O PRMD contribui para a competitividade e longevidade da IES (sobrevivência e avanço). \\
\hline
\end{tabular}

Fonte: Programa de Reconhecimento do Mérito Docente - PRMD da IES Pesquisada

Os respondentes da pesquisa qualitativa foram três membros da Alta Direção responsáveis pelo planejamento e pelas estratégias da Instituição. Esses membros foram escolhidos intencionalmente, pois atuam ativamente na criação de programas em prol da valorização e reconhecimento dos docentes.

A população da pesquisa quantitativa foi composta por um universo de 743 (setecentos e quarenta e três) professores de diversos cursos distribuídos nas 14 unidades da instituição. A amostra foi não probabilística por acessibilidade. Da população de 743 professores, 162 participaram da pesquisa. Os participantes da pesquisa retratam 0 universo pesquisado, proporcionando uma confiança de $95 \%$, com uma margem de erro de $6,8 \%$ para mais ou para menos. O questionário foi desenvolvido pelos participantes da pesquisa, com base nas dimensões propostas no PRMD objetivando avaliar suas opiniões com relação aos critérios propostos pela instituição para reconhecimento dos docentes pela meritocracia.

\section{Análise e discussão dos resultados}

Os resultados da pesquisa de campo sinalizaram que o PRMD implantado na IES possui vários pontos positivos, porém, na percepção da Alta Direção e dos Docentes, algumas questões necessitam de melhorias para que fiquem alinhados às estratégias institucionais e aos interesses dos Docentes.

\subsection{Análise da percepção da diretoria}

Com a finalidade de compreender melhor a estratégia da diretoria da IES pesquisada na aplicação do PRMD, foram entrevistados três funcionários da alta administração. Esses funcionários foram entrevistados em momentos diferentes, porém o resultado, apresentado a seguir, contempla a análise de todos.

Foi possível constatar que o fator motivacional que levou a instituição a implementar o PRMD foi a possibilidade de valorização dos docentes não só em função do trabalho já desenvolvido por eles na instituição, mas também por outras atividades extraclasses desenvolvidas 
que são tão importantes quanto as internas, e que agregam valor não só para eles, como também para a instituição. Seguindo esta visão, foram definidos pelos gestores dois objetivos para servir de norteadores:

Objetivo 1: Promover melhoria do corpo docente através do reconhecimento das pessoas que mais se destacam. Os gestores acreditam que os resultados apareçam a médio e longo prazo, tendo como benefício à melhoria do corpo docente.

Objetivo 2: Alinhar a prática docente ao projeto institucional, assim o professor passará a ser mentor. Com este propósito, os docentes ficarão mais estimulados e buscarão se alinhar às questões institucionais.

O diretor consolidou os objetivos dizendo: as pessoas que não estão estimuladas serão estimuladas e, com o passar do tempo, os estímulos se estenderão praticamente a todos. Este processo fará com que os docentes busquem o aprimoramento e, assim, atuarão melhor e haverá melhoria do corpo docente (DIRETOR EXECUTIVO, 2017).

Já a Assessora da Vice-Presidência corroborou afirmando: "Para a instituição é muito importante que o professor queira continuar trabalhando conosco, que haja fidelização, não preferindo ir trabalhar em outra IES".

Outro fator importante observado pelos gestores e que não estava entre um dos objetivos iniciais do projeto foi à obtenção de informações relevantes que passaram a integrar o sistema interno. Após a implantação e execução do PRMD, observou-se que informações de atividades relevantes praticadas pelos docentes fora da instituição não estavam inseridas no sistema interno, informações que contribuem e agregam valor para a instituição e que só poderiam ser obtidas através dos docentes.

A Alta Direção salientou que o programa retratou os pontos fortes e fracos da instituição quanto às diretrizes institucionais, tendo os gestores ficado satisfeitos com o resultado final obtido. Proporcionou à Instituição uma visão dos seus pontos positivos e negativos: alguns procedimentos precisam ser mantidos, outros devem ser aperfeiçoados. O programa trouxe informações importantes de seus docentes, que passaram a ser conhecidos com mais detalhes. Esse melhor conhecimento do corpo docente, como um todo, deu condição de entendê-lo melhor.

De acordo com a Alta Direção, com a internalização dessa cultura do reconhecimento por meritocracia, os docentes propagarão essa visão valorativa da IES, que vai repercutir positivamente entre os colegas de trabalho da instituição e também em outras, já que muitos deles possuem vínculo com mais de uma IES. Será um processo que, com o passar do tempo, atingirá também os alunos, que, ao sentirem que o corpo docente se fortalece e se destaca entre os demais, farão o marketing "boca a boca" contribuindo para o reconhecimento e crescimento da instituição.

Com base na experiência atual, experiência adquirida com o primeiro PRMD, a Alta Direção afirmou que, no próximo PRMD, não haverá muita dificuldade, pois recorrerão às lições aprendidas. Também confirmou que, para o próximo PRMD, serão realizadas algumas 
mudanças, melhorias para que fiquem alinhadas às estratégias institucionais. Vasconcelos (2000) corrobora Terra (2000) ao ressaltar que o nível estratégico da empresa é extremamente importante. Nela são definidos os campos do conhecimento que centralizam o aprendizado.

\subsection{Análise da percepção dos docentes}

Para avaliar a percepção dos docentes, com relação aos critérios propostos no PRMD, foram analisados os dados da pesquisa quantitativa com o uso do questionário.

O PRMD possui dimensões: dimensão pedagógica, dimensão envolvimento, dimensão mentoria e dimensão avaliação de desempenho, que buscam agrupar e mensurar os Ativos Intangíveis da IES pesquisada, com a finalidade de valorizar o corpo docente, seu principal colaborador, por meritocracia.

O resultado da análise por dimensão sinalizou que a grande maioria dos docentes concorda parcialmente que a dimensão pedagógica engloba todas as categorias necessárias para reconhecimento por meritocracia, obtendo a proporção mais alta com um percentual de 43,2\% dos docentes, seguido pelos que concordam totalmente, com o percentual de $19,1 \%$. No extremo estão os docentes que discordam totalmente com $3,1 \%$ e discordam parcialmente com $9,3 \%$ dos respondentes.

A avaliação da Dimensão Envolvimento obteve um resultado melhor em relação à dimensão anterior, sendo que $45,1 \%$ dos docentes concordam parcialmente com o fato de que essa dimensão possuía as categorias necessárias para reconhecimento por meritocracia, seguido por $16,7 \%$ dos docentes, cuja concordância é totalmente. Em um percentual menor de $3,7 \%$ estão os que discordam totalmente; com percentual de $9,3 \%$ os que discordam parcialmente.

A Dimensão Mentoria obteve o melhor resultado, quando observados os docentes que concordam totalmente na proporção de $26,5 \%$ e $38,3 \%$ dos docentes que concordam parcialmente em relação ao fato de que as categorias dessa dimensão são reconhecidas como meritocracia. Com percepção contrária, estão os demais docentes com $3,7 \%$ que discordam totalmente e $8,6 \%$ que discordam parcialmente.

Das quatro dimensões avaliadas, a Dimensão Avaliação de Desempenho obteve o resultado menos favorável, com 33,3\% dos docentes que concordam parcialmente, seguido por $16,7 \%$ dos que concordam totalmente. Já os que discordam totalmente apresentam $4,9 \%$; os que discordam parcialmente apresentam $17,3 \%$. Entre as categorias, a maior rejeição está relacionada à consideração por avaliação e ao reconhecimento por meritocracia.

Dentro de uma visão geral, a Tabela 1 retrata a percepção dos docentes quanto ao PRMD, como um todo. 
Mensuração do Capital Intelectual Docente: Avaliação e Reconhecimento por Meritocracia em uma Instituição de Ensino Superior

Tabela 1 - Percepção Geral do PRMD

Fonte: Dados da pesquisa

\begin{tabular}{lc}
\hline \multicolumn{1}{c}{ Avaliação } & Frequência \\
\hline Discordo Totalmente & $7,0 \%$ \\
\hline Discordo Parcialmente & $13,0 \%$ \\
\hline Nem Concordo, Nem Discordo & $30,1 \%$ \\
\hline Concordo Parcialmente & $32,3 \%$ \\
\hline Concordo Totalmente & $17,6 \%$ \\
\hline
\end{tabular}

Pode ser observado que $20 \%$ dos respondentes são os que discordam (totalmente e parcialmente) do PRMD, porém, em uma proporção maior, estão os que concordam (parcialmente e totalmente) com o programa com 49,9\%. Com um percentual considerável de $30,1 \%$ estão os que ficaram em dúvida, compondo o quadro de docentes que nem concordam e nem discordam do PRMD.

A maioria dos docentes concorda que o PRMD contribui para a competitividade e longevidade da IES pesquisada. A proporção dos que concordam é mais que o dobro em relação à proporção dos que discordam da afirmativa (quando somado concordo totalmente com o concordo parcialmente e confrontado com a soma do discordo totalmente com discordo parcialmente). A gráfico 1 detalha a percepção dos docentes.

\section{Gráfico 1 - Contribuição do PRMD para a Competitividade e Longevidade} da IES

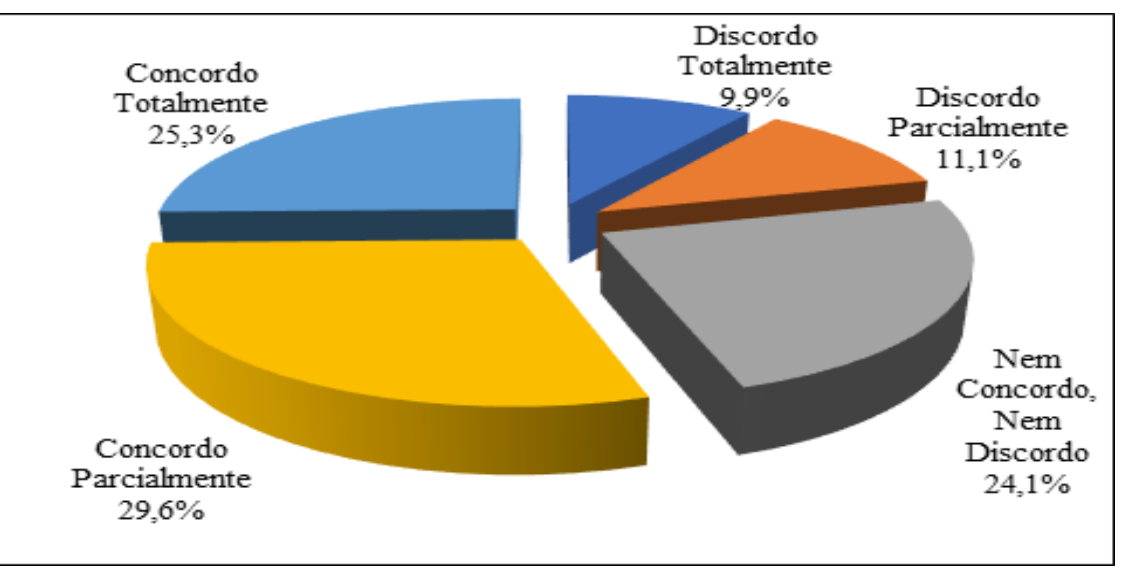

Fonte: Dados da pesquisa.

Como apresentado no Gráfico 1, grande parte dos docentes concorda em que o PRMD contribui para que a IES seja vista como instituição que os reconhece por meritocracia, sendo $25,3 \%$ dos docentes os que concordam totalmente e $29,6 \%$ os que concordam parcialmente, totaliza $54,9 \%$, quando somados. Na contramão, em uma proporção menor, estão os docentes que acham que o PRMD não contribui para a competitividade e longevidade da IES, sendo este percentual de $9,9 \%$ dos que discordam totalmente e $11,1 \%$ dos que discordam parcialmente, 0 
que totaliza a proporção de $21 \%$, quando agrupados. Dos docentes que ficaram em dúvida quanto à afirmativa abordada está a proporção de $24,1 \%$, sendo representados graficamente nos que "Nem concordam e Nem discordam".

Criar a cultura da meritocracia é importante para a organização. Segundo Terra (2000), a Cultura de uma organização é fundamental para o desenvolvimento de planos estratégicos baseados na ação, permitindo às equipes multidisciplinares terem alto grau de autonomia nas práticas inovadoras.

Os participantes da pesquisa reconheceram a importância de um acompanhamento dos docentes ao longo do semestre, validando não somente a realização das atividades previstas no Plano Pedagógico Curricular (PPC), mas sim valorizando as atividades inovadoras desenvolvidas por eles ao longo dos semestres. Os docentes ressaltaram a necessidade do uso de critérios que possibilitem avaliar na prática e não apenas em ações pontuais. Devem ser avaliadas as iniciativas do docente na sua rotina em sala de aula, no que tange às metodologias ativas, além das iniciativas de trabalhos inovadores e relevantes.

\subsection{Pontos de melhoria}

Na questão aberta, disponibilizada no final do questionário, vários docentes apontaram pontos passíveis de melhoria, que são destacados abaixo. As opiniões foram agrupadas para melhor entendimento.

\section{Amplitude na participação dos docentes}

Alguns docentes sugeriram que a construção do PRMD fosse aberta para recebimento de propostas, o que lhes permitiria envolver-se no processo e, de maneira colaborativa, criar um instrumento com a identidade de todos. Expandir as dimensões e categorias aumentaria 0 número de participações e reduziria a possibilidade de haver limitações nos indicadores. Ressalta-se aqui os autores Bassan e Hauschildt (2005), para os quais as pessoas têm importância nas organizações e também são responsáveis por produzirem o Capital Intelectual que geram o conhecimento e habilidades que proporcionam 0 seu diferencial competitivo. O depoimento abaixo ilustra a opinião de um docente:

"Seria louvável permitir a participação dos professores na construção do programa com o objetivo de ouvir as propostas e deixar o PRMD alinhado com as estratégias institucionais e aos interesses dos docentes. Limitar o número de participações reduz a possibilidade de identificar discordâncias no processo e limitações nos indicadores".

\section{Comunicação}

Ficou explícito que é preciso ter mais transparência e clareza das metas e objetivos a serem atingidos, em relação aos aspectos qualitativo e quantitativo. Faz se necessária a divulgação ampla do PRMD, com os 
processos de mensuração e desempenho, e da premiação ofertada no programa. Muitos professores salientaram que não conheciam com detalhamento o PRMD e, como exemplo, afirmaram que

"até docentes premiados não souberam explicar os critérios e pontuações das dimensões e categorias que obtiveram para a premiação, não sabendo a razão de terem sido premiados".

A IES pesquisada deveria criar mecanismos para fazer as informações chegarem aos docentes eficazmente. Os departamentos responsáveis pelos processos devem ser mais preparados para esclarecimento das dúvidas não somente do PRMD, mas também de eventos que ocorrem na instituição. Davenport e Prusak (1998) enumeram métodos importantes para melhoria da comunicação, tais como: contextualização; categorização; cálculo; correção e condensação.

\section{Critério de pontuação}

Os critérios apresentados no edital do PRMD foram muito questionados pelos docentes, que apontaram que os mesmos deveriam ser mais bem-definidos e ressaltaram um critério que deixou alguns docentes fora do programa: o fato de terem que se inscrever ao PRMD, critério este que muitos não observaram. Salientaram, também, a importância de novas dimensões, categorias e de um novo formato de pontuação, deixando o PRMD mais acessível e equilibrado com a distribuição de peso entre as categorias mais relevantes.

Os docentes propuseram melhoria no instrumento de avaliação institucional feita pelos discentes. Observaram que muitos deles não são orientados apropriadamente para utilizarem a ferramenta e, assim, acabam usando critérios fora do contexto, como, por exemplo:

"pune o docente (atribui nota ruim) devido à aplicação de alguma regra institucional aplicada pelo docente e que o discente achou injusta".

\section{Currículo Lattes}

Foi sugerido também o aperfeiçoamento do processo para o cadastro das atividades, utilizando o currículo Lattes como instrumento de coleta de dados, pois ele trará praticamente todas as atividades acadêmicas dos docentes. O uso deste documento evitaria preenchimento redundante, não havendo a necessidade de duas plataformas.

\section{Políticas internas}

Foi ressaltada a necessidade de evitar o estímulo excessivo da competitividade entre os docentes e estimulá-los a cooperarem. A cooperação entre os indivíduos permite 0 compartilhamento das habilidades e dos conhecimentos, capacitando-os intelectualmente, e 
agregando valor para o profissional e a instituição (MOLLERSTRAND, 2003).

Foi considerada a importância de não só se ter coerência nos resultados dos programas de meritocracia, mas também da premiação. Não se deve agir de forma contrária, como por exemplo: desligar docentes recém-premiados em curto espaço de tempo, sem causa pertinente para a tal ação. Ação como essa leva a maioria dos docentes a crer que o programa é falho, fazendo-os questionar o motivo de se desligar um docente recém-premiado. É importante a divulgação dos critérios, os reais motivos, para essa desvinculação. Fica a pergunta: A premiação teria sido fidedigna ou tratava-se de mera ação institucional?

Sabe-se que a burocracia nos procedimentos para mensurar o Capital Intelectual consiste na dificuldade para registrá-los. Por mais perceptível que seja a valorização dos Ativos Intangíveis, existe muita dificuldade para mensurá-los e registrá-los (FEITOSA, 2015).

\section{Sistema de informação}

Foi constatada a necessidade do desenvolvimento de um sistema que automatize as atividades realizadas pelos docentes dentro da própria IES, através de uma inserção automática, não necessitando do preenchimento por parte do docente. Outro processo importante a ser implementado é a inclusão automática do docente no PRMD, dando a ele a opção de não participação no programa, caso não tenha interesse. Além de automatizar grande parte do processo, o sistema poderia disponibilizar para os docentes o seu score com a discriminação de todas as atividades realizadas, dando-Ihes a visão de tudo que está sendo pontuado, da forma mais simples, de modo a não os prejudicar caso algo não seja computado. Acima de tudo deve haver transparência em todos os processos e exige-se que o sistema seja confiável, evitando falhas que impliquem a avaliação incorreta das atividades cadastradas.

\section{Valorização dos colaboradores}

Foi identificada a necessidade de a IES valorizar mais os seus colaboradores, incentivando-os não somente em programas como 0 PRMD, mas dando a esses colaboradores o que é necessário no desenvolvimento de um bom trabalho. É louvável conhecê-lo mais de perto e mostrar que ele é importante para a instituição. Além disso, devem-se criar processos que evitem a diferenciação de cursos e áreas do conhecimento dentro da própria instituição, na qual alguns, por serem estrategicamente bem-vistos, acabam recebendo mais recursos que outros, que, no entanto, seriam igualmente merecedores de atenção. Espera-se que cada indivíduo contribua com o seu potencial único, pois esse tipo de recurso é de difícil absorção por parte dos concorrentes, possibilitando ampliar receitas e capacidade inovadora (PEREIRA et. al, 2015). 


\section{Considerações finais}

O estudo teve como objetivo analisar a aplicação do Programa de Reconhecimento do Mérito Docente - PRMD em uma IES, visando à avaliação e ao reconhecimento dos professores por meritocracia. Outros objetivos foram: conhecer a estratégia da diretoria da IES na aplicação do Programa; analisar a percepção dos docentes da IES com relação aos critérios propostos e identificar possíveis melhorias para o Programa.

A fim de atingir esses objetivos, a primeira etapa da pesquisa possibilitou entender as características da sociedade do conhecimento e a natureza dos ativos intangíveis (AI). Esta etapa permitiu, igualmente, detalhar os desafios da mensuração dos AI tanto na contabilização quanto nos processos de medição e agrupamentos. Foram apresentados modelos para avaliação dos AI e, em especial, os que possam ser aplicados à mensuração do Capital Intelectual Docente. O modelo que se destacou foi o modelo proposto por Peroba (2013), isso devido à sua relação com o objetivo geral.

Ao se analisar as estratégias da diretoria para a aplicação do PRMD, concluiu-se que um dos fatores motivacionais foi promover a valorização do corpo docente, avaliando-o pelo desempenho interno e pelas atividades externas (extraclasse). Os principais objetivos do Programa foram: promoção de melhoria do corpo docente através do reconhecimento dos profissionais que se destacam; alinhamento das práticas dos docentes de acordo com os projetos institucionais e obtenção de informações importantes e que agregam valor para os docentes e para a instituição, informações estas que só poderiam ser fornecidas pelos próprios docentes.

Importante ressaltar que antes da proposição do PRMD, a IES pesquisada realizou um benchmarking em diversas outras IES e empresas para a obtenção das melhores políticas de meritocracia, que se identificassem com a instituição. Com base nas melhores práticas foi que se criou o Programa que permitiu a identificação e mensuração das atividades geradoras do CI.

A percepção geral dos docentes em relação ao programa foi: 49,9\% dos respondentes concordam parcialmente/totalmente; 20\% discordam totalmente/parcialmente e 30,1\% ficaram em dúvida.

Com base na percepção da Alta Direção e dos docentes, chegou-se à conclusão de que o programa implantado trouxe muitos pontos positivos, porém precisa de algumas melhorias para se adequar às estratégias institucionais e aos interesses dos docentes. Em relação a vários pontos, houve consenso na visão dos envolvidos (alta diretoria e docentes), quanto ao que deve ser melhorado nos próximos programas desta natureza.

Constatou-se que a avaliação e o reconhecimento por meritocracia têm fundamental importância em todas as dimensões no processo avaliativo do capital intelectual. Os principais desafios constatados foram: a necessidade de melhoria da divulgação/comunicação junto aos docentes, melhor aceitação do programa por parte deles, clareza no 
critério de elegibilidade dos docentes para participação e a sistematização da coleta de dados para a mensuração e a avaliação. Por outro lado, o Programa trouxe para a instituição mais conhecimento quanto aos seus pontos fortes e fracos e pôde conhecer melhor os seus docentes. Possibilitou à Alta Direção valorizar os professores pela meritocracia. Os diretores chegaram à conclusão de que, com a internalização desse programa e de outros programas semelhantes, haverá agregação de valor para todos os envolvidos, proporcionando o crescimento institucional.

Concluiu-se que os indicadores do Programa para reconhecimento do mérito docente são, na sua maioria, adequados para a mensuração do Capital Intelectual Docente. Observou-se que alguns desses indicadores foram adaptados para serem tratados estatisticamente e poderiam ser analisados também de forma qualitativa, conforme praticado por Peroba (2013).

Importante parabenizar a IES pesquisada pela inovação na proposição do PRMD, disposição em participar da avaliação do mesmo e ainda pela boa vontade na recepção e implementação das sugestões de melhoria.

\section{Referências}

BASSAN, C. C.; HAUSCHILDT, R. Mensuração do capital intelectual: um desafio importante para a contabilidade. Revista Eletrônica de Contabilidade, [s.l.], v. 1, n. 2, p. 91-106, 2005. Disponível em: https://periodicos.ufsm.br/contabilidade/article/view/72/3734. Acesso em: 27 mar. 2016.

BEUREN, I. M.; IGARASHI D. C. C. A importância dos intangíveis nas empresas e a sua relação com a contabilidade. Revista do Conselho Regional de Contabilidade. [s.l.], 2002.

CAJUEIRO, J. L. G. Modelo de gestão do conhecimento para instituições de ensino superior. 2008. Tese (Doutorado em Engenharia da Produção) Universidade Federal de Pernambuco, Recife, 2008.

COLLIS, J.; HUSSEY, R. Pesquisa em Administração: um guia prático para alunos de graduação e pós-graduação. Porto Alegre: Bookman. 2005.

DAVENPORT, T. H.; PRUSAK, L. Conhecimento empresarial: como as organizações gerenciam o seu capital intelectual. Rio de Janeiro: Campus. 1998.

EDVINSSON, L.; MALONE, M. S. Capital Intelectual. São Paulo: Makron Books. 1998.

FEITOSA, M. O. Importância do capital intelectual em uma instituição de ensino superior de uma cidade do nordeste brasileiro. 2015. Dissertação (Mestrado Profissional em Administração) - Universidade Potiguar, Natal, RN, 2015. 
Gomes, P. W. R. Uso de indicadores e capacitadores do conhecimento para a competitividade do centro universitário UNA. 2014. Dissertação (Mestrado Profissional em Administração) - Fundação Cultural Dr. Pedro Leopoldo, Pedro Leopoldo, 2014.

JORDÃO, R. V. D.; SOUZA, A. A. Aquisição de empresas como fator de mudança no sistema de controle gerencial: uma análise estratégica sob a perspectiva da teoria contingencial. Revista Universo Contábil, [s.l.], v. 9, n. 1 , p. 75-103, 2013.

JORDÃO, R. V. D.; CASAS NOVAS, J. L. P. M. M.; SOUZA, A. A, ; NEVES, J. T. R. Controle do capital intelectual: um modelo aplicado à gestão dos ativos do conhecimento. Revista Ibero-Americana de Estratégia, [s.l.], v. 12, n. 2, p. 195-227, 2013. Disponível em:

http://www.spell.org.br/documentos/ver/16911/controle-do-capitalintelectual--um-modelo-aplicado-a-gestao-dos-ativos-do-conhecimento.

Acesso em: 13 mar. 2017.

MARCONI, M. A. ; LAKATOS, E. M. Metodologia científica. 6. ed. São Paulo: Atlas, 2011.

MARTINEZ, A. L. Measuring and reporting intellectual capital: the highest management accounting challenge for the next millennium. In:

CONGRESSO INTERNACIONAL DE CUSTOS, 6., 1999, Braga. Anais [...]. [S.I.: s.n.], [1999?].

MELO, V. L. T. Avaliação e gestão do capital intelectual \& geração de valor em fusões e aquisições: uma experiência de sucesso em uma instituição financeira de grande porte. 2015. Dissertação (Mestrado Profissional em Administração) - Faculdades Integradas de Pedro Leopoldo, Pedro Leopoldo, 2015.

MOLLERSTRAND, R. J. Gestão do conhecimento: o impacto das diferenças culturais na gestão do conhecimento das empresas. 2003. Dissertação (Mestrado em Administração da Produção e de Operações Industriais) Fundação Getúlio Cargas, São Paulo, 2003.

OLIVEIRA, M. M. Como fazer pesquisa qualitativa. Petrópolis: Vozes, 2007.

PEREIRA, A. A.; MAFRA, F. C. ; VASCONCELOS, M. C. R. L. ; FERREIRA, M. A. O Contexto capacitante e a construção do conhecimento organizacional: um estudo de caso sobre condições capacitadoras e capacitadores na DICON/UFS]. Revista Gestão \& Tecnologia, [s.l.], v.15, n. 1, p. 276-297, 2015.

PEROBA, T. L. C. Modelo de avaliação de capital intelectual para os cursos de mestrado profissional em administração: uma contribuição para a gestão das instituições de ensino superior. Tese (Doutorado em 
Administração) - Fundação Getúlio Vargas, Escola Brasileira de Administração Pública e de Empresas, Rio de Janeiro, 2013.

RITTA, C. O.; ENSSLIN, S. R. Investigação sobre a relação entre ativos intangíveis e variáveis financeiras: um estudo nas empresas brasileiras pertencentes ao índice IBovespa nos anos de 2007 e 2008. CONGRESSO USP DE CONTROLADORIA E CONTABILIDADE, 10., 2010, São Paulo. Anais [...]. [S.I.: S.n.], [2010?].

SINDICATO DOS PROFESSORS DO ESTADO DE MINAS GERAIS. Convenção Coletiva de Trabalho 2015/2017. Belo Horizonte: Sinpro, 2015. Disponível em: http://sinprominas.org.br/wpcontent/uploads/2015/06/CCT-MG-2015-2017.pdf. Acesso em: 16 jun. 2015.

STEWART, T. A. Capital intelectual, intellectual capital. Tradução de Ana Beatriz Rodrigues, Priscila Martins Celeste. Rio de Janeiro: Campus, 1998.

TERRA, J. C. C. Gestão do conhecimento: o grande desafio. São Paulo: Negócio, 2000.

VASCONCELOS, M. C. R. L. Cooperação universidade/empresa na pósgraduação: contribuição para a aprendizagem, gestão do conhecimento e inovação da indústria mineira. 2000. 257f. Tese (Doutorado em Ciência da Informação) - Universidade Federal de Minas Gerais, Belo Horizonte, 2000.

VERGARA, S. C. Métodos de pesquisa em administração. 6. ed. São Paulo: Atlas. 2015. 